\title{
Adoption of Collaborative Technology to Enhance Master Data Quality Across Municipal Administrations - Identifying Drivers and Barriers
}

\author{
Christian Meske \\ University of Duisburg-Essen \\ christian.meske@uni-due.de
}

\author{
Robert Heidekrüger \\ University of Muenster \\ robert@heidekrueger.net
}

\author{
Tobias Brockmann \\ innoscale AG \\ brockmann@innoscale.de
}

\author{
Matthias Czerwonka \\ innsocale AG \\ czerwonka@innoscale.de
}

\author{
Stefan Stieglitz \\ University of Duisburg-Essen \\ stefan.stieglitz@uni-due.de
}

\begin{abstract}
In recent years, software for collaborative improvement of master data quality has been increasingly introduced into public administration. With the support of this collaborative software, master data is not only managed by one stakeholder such as an individual or department but rather crossinstitutionally and across departments by groups of several stakeholders, e.g. several municipal authorities. In this paper, based on the TechnologyOrganization-Environment Framework, both driving forces as well as obstacles were identified, which influenced the adoption of such collaborative software. The results show, that positive factors concerning the adoption are perceived barriers, presence and importance of data standards as well as the successful implementation into the existing environment, whereas a complex IT-infrastructure impedes an introduction.
\end{abstract}

\section{Introduction}

Public administrations consist of a huge number of specialized departments such as a citizen registration or building department. Typically, each department has its own specialized software to support their work. For instance, in Germany public administration often uses more than 80 different software systems [1]. Hence it is not surprising that about 20.4 billion Euros was invested in Germany's information and communication technology services by the federal, state and municipal authorities in 2013, with an additional annual increase. Thus public administration accounts for one fifth of the information technology and telecommunication market in Germany [2]. Public administration operates an IT Infrastructure worth billions in order to optimize internal processes as well as service provisions for citizens [3]. In this context, a large amount of master data needs to be administered. The processing of extensive databases in different heterogeneous information systems requires a high master data quality and level of IT integration, especially for the exchange between several departments of public administrations [4]. Moreover, public administrations strive to be more citizen-oriented and to offer better service, besides saving costs to cope with reduced budgets. Improving processes and IT support as well as finding new organizational concepts is a logical next step. ECollaboration to improve master data quality within public administration is increasingly important, which requires interoperability of existing systems as well as standardization of data. For according technology, the term CDMS (Collaborative Data Management Software) is used in this paper. At the same time, public institutions often resist to introduce new technology because of different and often contextual reasons. Hence, we aim to identify drivers and barriers that influenced the adoption of CDMS in the surveyed instutions. The research question to be answered is:

Which factors have an influence on the adoption of CDMS in public administrations?

In this work, the Technology-OrganizationEnvironment (TOE) Framework of Tornatzky and Fleischer [6] was chosen as the theoretical foundation, which was successfully applied in several studies (e.g. [7]; [8]; [9]). In this theoretical context, 8 hypotheses regarding influencing factors on the adoption decision are formulated. Factors influencing the decision to adopt CDMS are identified based on an online survey of 103 persons responsible for IT and organization from German municipal authorities. The remainder of this paper is structured as follows: In section 2, a literature review on E-Collaboration in public administration as well as data governance and collaborative data management will be conducted. In section 3, the theoretical background (TOE framework) of this study will be discussed and the hypotheses derived. The results of the survey will be shown in section 4, followed by their discussion and critical 
reflection in section 5 . In section 6 , the results are summarized, limitations are discussed, the contribution to research is illustrated and an outlook on further research is given.

\section{Literature Review}

\subsection{E-Collaboration}

The general interaction of different organizations in order to achieve joint goals that are supported by information technology is discussed under the term of E-Collaboration in literature ([10]; [11]). ECollaboration can be defined as "direct and mutually influenced activities of two or more persons with common goals in order to manage a task or solve a problem. It can be conducted within a commonly designed and negotiated computer-mediated context and by using shared resources" ([11], p. 47). ECollaboration includes networking of business processes across organizations as well as enabling and supporting of communication and collaboration, e.g. through Groupware [11]. Such computer-mediated communication, collaboration and networking can be affected by formal as well as informal influences like the organizational hierarchy or level of activity ([12]; [13]). Hence, E-Collaboration enables a company-wide integration of teams and departments, what in turn can lead to unexpected serendipity [14]. While this particular research area mainly focuses on communication platforms and Groupware systems [15], the synchronization of data repositories is considered a basis for such systems [16]. Hence, the improvement of master data quality could not be identified as an object of research on E-Collaboration. Only the common use and processing of documents seems to be a central research aspect in this field [17]. In addition to process optimization in value chains, current research on E-Collaboration deals with Interorganisational Information Systems (IOIS) [18] and electronically supported Knowledge Management within and beyond organizations ([19]; [20]). The application of E-Collaboration as a mediator can improve the data exchange about ten percent in time variances compared to non-E-collaboration [21]. However, in order to ensure the functioning of electronic collaboration, the importance of high data quality and the necessity of standardization are emphasized [4].

Besides the lack of literature focusing on master data management in the context of E-Collaboration, evidence of collaborative work, especially in German public administrations is found in different sources of literature. It is often connected with the term Electronic Government (E-Government). According to the definition of von Lucke and Reinermann ([22], p. 1), E-Government can be understood as the "handling of business processes in connection with governance and administration (Government) by means of information and communication technology through electronics." This is accompanied by the opportunity to facilitate the use and processing of information, which in turn increases the effectiveness and efficiency of administrational tasks [23]. In this context, professionalism, efficiency, service and engagement are identified as value positions concerning EGovernment [24]. It has been shown that coercive and normative pressure positively affects the adoption of EGovernment in public administrations [25]. Though in all studies master data are necessary resources, they are not the primary research objects.

\subsection{Collaborative Master Data Management and Data Governance}

Researchers have investigated collaboration in the domain of public administrations from different perspectives: e.g. collaboration as an answer to demographic change [26] or cross-sector collaboration on public administration infrastructure. However, our literature review revealed that insufficient research in the area of collaborative improvement of master data quality in public administrations has been conducted. Approaches for collaboration on master data management have mainly been discussed in business contexts so far. Focusing the literature review to collaborative (master) data management in public administration, we could not identify relevant previous work. Hence, we broadened the search to all kinds of organizations. In the interaction of several organizations or branches, the use of data plays an increasingly important role [4]. The synchronization or common utilization of databases is seen as fundamental for the concept of E-Collaboration [16]. However, the term collaborative (master) data management is rarely used in literature: intercompany data management or global data synchronization between trading and industrial organizations is mentioned more often (e.g. [25]). Variations within bilateral and multilateral exchanges of data emerge when approaching solution questions. Collaborative customer relationship management (CRM) appeared being related to collaborative master data management. Schellong and Mans [27] identified the need for a collaborative CRM approach of public administrations to enable 
government services via preferred channels. They further strengthen the requirement of collaboration between all government levels. Still, it has also been challenged whether collaborative CRM systems are able to support inter-organizational collaboration [28].

Emphasizing the role of master data in service processes, Loser et al. [29] present four different architecture approaches for the distribution of master data in intra-organizational collaboration settings: (1) Central Master Data System, (2) Leading System, (3) Master Data Harmonization via Standards, and (4) Repository. While different standards are used in the bilateral exchange, in the multilateral approach a master data pool functions as an intermediary reducing the number of interfaces and standardizing processes, functions, and data. The m:n-connections deemed problematic of the multilateral approach could be solved by the concept of Global Data Synchronization Network (GDSN). Therein about 25 (status 2008/2009) certified data pools are aggregated in a global directory that is operated by the standardization organization GS1.

Related to data management in general and to collaborative master data management in particular is the concept of Data Governance. Otto and Weber [31] conceive of Data Governance as a framework for the definition of tasks and responsibilities within Data Quality Management (DQM) and which includes three design elements: (1) the tasks to be fulfilled within the scope of DQM, (2) the development of a data quality strategy, and (3) the definition of data maintenance processes. Effective data management requires a data governance structure and framework to achieve the determined goals of the organization ([32]; [33]). Still, Data Governance also relies on technology solutions e.g. for assessing the data quality [34].

\section{Theoretical Background and Hypotheses}

\subsection{Technology-Organization-Environment Framework}

The Technology-Organization-Environment (TOE) framework was chosen as the theoretical basis for an examination of influencing factors for the adoption of CDMS in public administrations. The framework distinguishes three contexts which influence the decision regarding the adoption of a technological innovation within an organization: (1) the technological context, (2) organizational context, and (3) external environment [6].
The technological context includes all internal and external technologies with relevance for the organization, including current internal practices and equipment [36], and all technologies that are externally available to the organization ([37]; [38]). The organizational context refers to descriptive characteristics of the organization such as size, degree of centralization and formalization, management structure, quality of work force, and available resources. The context of the external environment includes all externally influencing factors such as the industry in which the organization operates, its competitors and partners, access to external resources and legal requirements [6].

To explain the adoption of technologies and systems, several researchers have applied the TOE framework in the context of various domains, for example in terms of the adoption of complex innovations [39], in electronic data interchange [9], in open systems [7], as well as in association with Internet [40], e-Business ([41]; [42]), e-Procurement [43], RFID ([44]; [45]) or Social Networking Sites [46]. Moreover it was used to explain the acceptance of IT-systems in public organizations. For instance, Troshani et al. [47] concluded that the most important variables for organizational adoption of Human Resources Information Systems (HRIS) in the Australian public sector are organizational fit, management commitment, adoption pressure, and the urgency to achieve regulatory compliance.

\subsection{Hypotheses}

In their publication on the investigation of adoption of Open Systems, Chau and Tam [7] slightly adjusted the original TOE framework, in which they renamed the technological context to innovation characteristics of the introduced technology and the organizational context to organizational technology. Following Chau and Tam [7], the three contexts are adapted for this work and described as Innovation Characteristics, Organizational Technology, and External Environment.

Within these three contexts, eight factors (constructs) are proposed to have an influence on the adoption of CDMS (see also figure 1), which will now be described in detail. For an overview of all corresponding survey items, scales and sources, please see appendix A. 


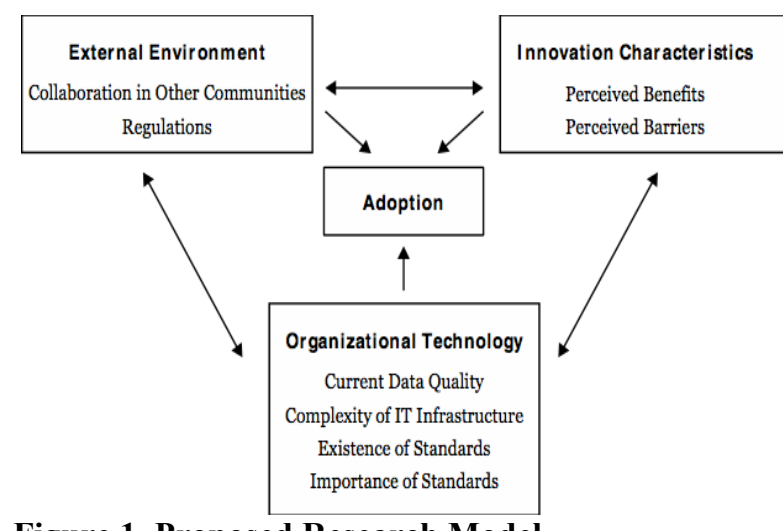

Figure 1. Proposed Research Model

3.2.1. Innovation Characteristics. This category refers to the perception toward the adoption of the system by users. A software solution for collaborative maintenance and improvement of master data quality in public administrations (CDMS) is a new and so far rarely examined approach. Thus it can be considered a technological innovation. The innovation does not have to be a new technology on the market as long as the idea, approach, or technology is perceived to be new by the user [14]. Following Chau and Tam [7] and Iacovou et al. [8], the model is developed by the constructs (1) Perceived Benefits and (2) Perceived Barriers: perceived benefits refer to the advantages that can be gained through the usage of CDMS, such as an improved productivity of users. Perceived barriers refer to obstacles of using CDMS, e.g. high implementation efforts. We expect that the stronger the different advantages of a software for the collaborative data management are perceived, the more likely is a positive influence on the decision for adoption [7]. Likewise following Chau and Tam [7] and Thong [14], the decision for the implementation of CDMS can be connected with perceived barriers. As a consequence, a negative influence on the decision for the implementation is expected with an increasing perception of barriers. As a result the following hypotheses are formulated:

H1: The perceived benefits influence the adoption of CDMS positively.

H2: The perceived barriers influence the adoption of CDMS negatively.

To measure perceived benefits, participants were asked to rate the benefits for employee productivity and service delivery on a Likert-7 scale. The Likert-7 scale was used with reference to similar studies of technology adoption (e.g. [48]; [49]) and to increase the variance in our measure. Asking participants to rate implementation effort and the willingness of employees to use the corresponding software on a Likert-7 scale operationalized the perceived barriers.

3.2.2. Organizational Technology. In the context of organizational technology, the creation of individual constructs is mandatory because the subject has been examined insufficiently so far. It is expected that high rated master data quality currently positively correlates with the decision for implementation of CDMS. Besides (3) Current Master Data Quality, another factor is the (4) Complexity of IT Infrastructure in the organization. Chau and Tam [7] introduce this aspect in their study on adoption of Open Systems and hypothesize that a high complexity of IT-Infrastructure facilitates the decision to implement such systems because the organization may have sufficient experience with the implementation of new systems. Consequently, we derive the following hypotheses:

H3: A currently high master data quality influences the adoption of CDMS positively.

H4: A high complexity of the IT infrastructure influences the adoption of CDMS negatively.

Current master data quality was measured by asking participants to rate the current level of data quality in different dimensions (accuracy and completeness) adopted from Wang and Strong [50] on a Likert-7 scale. In order to measure the complexity of the IT infrastructure, participants were asked to state how many different systems ("Fachverfahren") and file formats were being used in their local authority.

Studies investigating the adoption behavior of organizations regarding technological innovations also consider standards as influencing factors, such as Chau and Tam [7] and Ortbach et al. [51]. A certain influence on the adoption of CDMS can be expected by the (5) Existence of Data Standards for the handling of data in the organization. As a result, it is assumed that the importance that is attributed by the users to these standards has an influence on the decision to adopt supporting software, resulting in the construct (6) Importance of Data Standards. Correspondingly, the following hypotheses are proposed:

H5: The existence of restrictive data standards influences the adoption of CDMS positively.

H6: The perceived importance of data standards influences the adoption of CDMS positively.

Both the existence and importance of standards were measured by asking participants to rate the existence and importance of standards for the (1) the collection (methods, processes), (2) filing (formats, structure), (3) and exchange with other organizations on a Likert-7 scale (self-developed construct). 
3.2.3. External Environment. Tornatzky and Fleischer [6] consider factors of the industry in which an organization acts, its competitors as well as guidelines by the government as a part of the external environment. Other publications that are based on the TOE framework also take into account the context of external pressure created by business partners ([8]; [9]). This results in the construct (7) CDMS-Usage in Other Public Administrations. Therefore, it can be assumed that the knowledge of the use of CDMS in other communities could exert a certain pressure to implement such a solution as well. A positive impact on the implementation decision by such an external pressure is expected. CDMS-usage was measured by asking participants, to which extent other municipal administrations use CDMS intra- or interinstitutionally (self-developed).

Moreover, the effects of legal guidelines mentioned by Tornatzky and Fleischer [6] in connection with the public administration play a special role because it is strongly regulated [3] and a negative influence is especially assumed through (8) Strict Data Protection Directives. In addition, internal guidelines for data protection of the community are taken into account. Therewith two more hypotheses can be proposed:

H7: The implementation of CDMS in other public authorities influences the adoption of such software into their own organization positively.

H8: Strict data protection directives influence the adoption of CDMS negatively.

To analyze information regarding collaboration in other local authorities, participants were asked to rate their level of agreement that other authorities improve their data quality collaboratively both internally and beyond their boundaries with other authorities on a Likert-7 scale. The influence of regulations was measured by asking participants to rate restrictions due to the strict data protection directives of the government and internal compliance regulations, both on a Likert-7 scale.

\section{Results}

The database of this study was compiled through an anonymous online survey conducted in January 2015. The questionnaire was sent to 1,070 public administrations. 142 full survey replies were received, resulting in a response rate of $13.3 \%$. The questionnaire consisted of two parts: the first one contained questions about the status quo together with the assessment of the potential for improving data quality. The second part enclosed questions regarding the identification of factors that could influence the implementation of a CDM software. In addition to the questions that are integrated in the research model, some control questions were gathered in order to be able to categorize the local authorities. According to the classification of the Communal Joint Office for Administrative Management (GGSt), local authorities in Germany can be divided into seven size classes by means of the number of inhabitants, such that class 7 represents the smallest size class with less than 10,000 inhabitants and class 1 the biggest with more than 400,000 inhabitants [52]. In order to eliminate extreme outliers huge administrations with more than 100.000 and very small ones were removed from the sample. As a result of the cleaning process overall 103 questionnaires of local authorities with 10,000-100,000 inhabitants were considered for the analysis. No demographic details of the respondents were asked for in the survey due to very strict data protection standards in German public administrations and to avoid interventions of the staff council.

We applied structural equation modeling based on the partial least squares approach (PLS-SEM), as according to literature PLS-SEM suits best for studies with a small sample size, which have only little theory or the goal is to extend an existing theoretical background [53]. In our analysis, Construct Reliability (CR) is assured as the respective values for all constructs are higher than 0.7 (Table 1). According to literature, Convergent Validity is given when items load highly on their associated factor. Values above 0.5 (ideally above 0.7 ) are accepted [7]. In our work, items with a factor loading less than 0.7 were removed from the model except for the item STIM2 (importance of standards for the storage of data), which demonstrated a factor loading of 0.64 . The item should be retained in order to measure importance of standards for the same categories as for the existence of standards. All items and their associated factor loadings are displayed in Table 2. Another indicator for Convergent Validity are values above 0.5 for the Average Variance Extracted (AVE), which is given for each factor as shown in Table 1. Discriminant Validity is achieved when an item correlates with items of the same construct rather than with items of other constructs [7]. It can also be demonstrated by comparing the square root of the AVE with the correlations of the constructs. As required for Discriminant Validity, the square root of the AVE (values on the diagonal line in Table 2) is greater than the correlations among constructs for all of our factors. Constructs with less than three items can be used in PLS-SEM as it is less restrictive than CB-SEM [54]. 
Table 1. Measurement Model Analysis and InterConstruct Correlations

\begin{tabular}{|l|l|l|l|l|}
\hline & CR & AVE & $\begin{array}{l}\text { standardized } \\
\boldsymbol{\beta}\end{array}$ & p-Value \\
\hline BEN & 0.89 & 0.80 & 0.028 & 0.37 \\
\hline BAR & 0.79 & 0.65 & -0.133 & 0.06 \\
\hline MDQ & 0.85 & 0.74 & -0.112 & 0.20 \\
\hline CIT & 0.83 & 0.71 & -0.144 & 0.04 \\
\hline EDS & 0.91 & 0.77 & 0.276 & 0.00 \\
\hline IDS & 0.83 & 0.63 & 0.169 & 0.07 \\
\hline OPA & 0.92 & 0.85 & 0.163 & 0.03 \\
\hline DPD & 0.84 & 0.73 & -0.072 & 0.25 \\
\hline BEN = Perceived Benefits, BAR = Perceived Barriers, \\
MDQ = Current Master Data Quality, CIT = Complexity of \\
IT Infrastructure, EDS = Existence of Data Standards, IDS \\
= Importance of Data Standards, OPA = CDMS-Usage in \\
Other Public Administrations, DPD = Strict Data \\
Protection Directives, CR = Construct Reliability, AVE = \\
Average Variance Extracted \\
\hline
\end{tabular}

Table 2. Construct Correlations

\begin{tabular}{|c|c|c|c|c|c|c|c|c|c|}
\hline & BEN & BAR & MDQ & CIT & EDS & IDS & OPA & DPD & $\mathrm{ADO}$ \\
\hline BEN & .89 & & & & & & & & \\
\hline BAR & .22 & .81 & & & & & & & \\
\hline MDQ & .09 & .19 & .86 & & & & & & \\
\hline CIT & .12 & -.14 & -.04 & .85 & & & & & \\
\hline EDS & .09 & .16 & .44 & -.16 & .88 & & & & \\
\hline IDS & .24 & .05 & -.08 & .36 & .11 & .79 & & & \\
\hline OPA & .24 & .19 & .08 & -.21 & .30 & .18 & .92 & & \\
\hline DPD & .19 & .25 & -.11 & -.13 & -.08 & -.16 & .02 & .85 & \\
\hline $\mathrm{ADO}$ & .15 & .24 & .04 & -.17 & .33 & .19 & .33 & .09 & 1.00 \\
\hline \multicolumn{10}{|c|}{$\begin{array}{l}\text { BEN = Perceived Benefits, BAR = Perceived Barriers, MDQ = } \\
\text { Current Master Data Quality, CIT = Complexity of IT } \\
\text { Infrastructure, EDS = Existence of Data Standards, IDS = } \\
\text { Importance of Data Standards, OPA = CDMS-Usage in Other } \\
\text { Public Administrations, DPD = Strict Data Protection Directives, } \\
\mathrm{CR}=\text { Construct Reliability, AVE = Average Variance Extracted }\end{array}$} \\
\hline
\end{tabular}

Regarding inter-construct correlation, all respective loadings were higher than the cross-loadings [55]. $\mathrm{R}$ squared is .24. The predictive relevance $\left(\mathrm{Q}^{2}\right)$ measures how well observed values are when reconstructed by a model. Values greater than 0 for $\mathrm{Q}^{2}$ imply predictive relevance [56]. Applying the Blindfolding Procedure of SmartPLS, predictive relevance for the model is demonstrated with $\mathrm{Q}^{2}=0.081$ (using an omission distance of $\mathrm{D}=7$ ). The results of the research model are displayed in figure 2 .

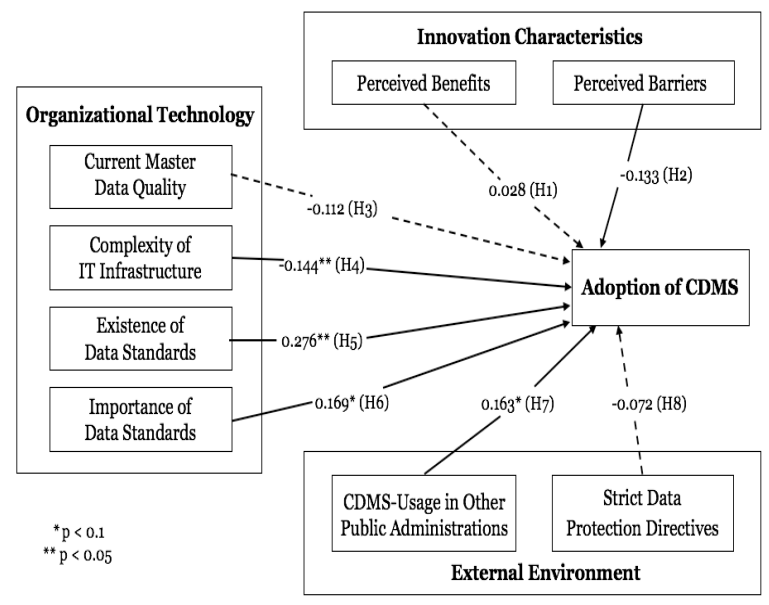

Figure 2. Research Results

The results show that in the context of the innovation characteristics, perceived barriers have a negative influence $(\beta=-.133, p<.10)$ on the adoption of CDMS so that hypothesis $\mathrm{H} 2$ can be confirmed. No confirmation could be found for the positive influence of perceived benefits on the decision to adopt $(\beta<.10$, $\mathrm{p}>.10)$ so that hypothesis $\mathrm{H} 1$ had to be refused.

Regarding organizational technology, a negative influence of the complexity of the IT infrastructure could be found $(\beta=-.144, p<.05)$, meaning that the probability of an adoption falls with an increasing complexity of the IT infrastructure. Further, a positive influence of the existence of standards $(\beta=.276, \mathrm{p}<.05)$ and a positive influence of the importance of standards $(\beta=.169, p<.10)$ could be determined so that the hypotheses H4, H5, and $\mathrm{H} 6$ can be supported. However, no significant influence of current data quality could be identified in this context, therefore the hypothesis $\mathrm{H} 3$ had to be refused.

With regard to the context of the external environment, a significant and positive influence of the external pressure through existing CMDMS usage in other local authorities could be derived from the analysis of data $(\beta=.163, p<.05)$, why hypothesis $H 7$ can be accepted as well. Yet, no significant support could be found for the hypotheses of the negative influence of guidelines so that hypothesis $\mathrm{H} 8 \mathrm{had}$ to be refused.

\section{Discussion}

\subsection{Innovation Characteristics}

In the context of the innovation characteristics, which comprise the perceived advantages and barriers 
of the implementation of the regarded software solution as suggested by Chau and Tam [7], a negative influence of perceived barriers on the implementation of CDMS can be proven. The effort of implementation is perceived as high, and the opinion that the willingness of the employees to use such software is low, represent obstacles for the implementation decision. The latter is not to be seen as a specific problem of the regarded approach, but rather as a general phenomenon in organizational changes and thereby in the adoption of new technologies [57] and requires a specific change in management in order to overcome this. The missing confirmation of a positive influence of the perceived advantages of the innovation can be due to the fact that the user of such software could not achieve the desired improvement in regard to the productivity of employees and service performance for the citizens or because these do not represent the aim of the implementation.

\subsection{Organizational Technology}

In regard to the organizational technology, the complexity of the IT infrastructure shows a negative correlation with the decision for the adoption of CDMS. Chau and Tam [7] predicted a positive correlation between IT complexity and adoption decision for the adoption of Open Systems technologies. However, they could not empirically confirm that. In the present paper, no prediction concerning the direction of the influence was given within the scope of the hypotheses, but only an influence was assumed. Against the background of the results, a higher complexity of the IT infrastructure in the form of a bigger size of used specialized procedures and file formats in the community has a negative impact on the adoption decision.

Considering the evaluation of the answers of users and non-users of common databases confirms that local authorities that maintain common databases with others operate specialized procedures less often than those who do not do this (figure 2). The empirical evaluation further indicates a positive correlation of the existence of standards together and store data as well as the exchange of data with other local authorities. This result confirms the hypotheses because the use of CDMS in the framework of E-Collaboration inevitably requires the use of standards [4].

We were also able to reveal an influence of the perceived importance of data standards for gathering and storage of data as well as regarding the exchange with other local authorities. This shows that the users of CDMS tend to rate the meaning of standards higher than those local authorities that do not use collaborative software. The operation of such software within or across local authorities requires a certain degree of standardization for the handling of data so that the shared utilization works. The influence of the current data quality in local authorities on the adoption decision turned out not to be significant. Taking into account the most frequently mentioned answers concerning the estimation of the data quality in regard to all eight dimensions, it becomes clear that the majority of the local authorities rates their own data quality as high. The relatively uniform rating of own data quality as high by users and non-users of a collaborative software solution for the improvement of data quality leads to a lack of a significant influence on the adoption decision. This raises the question of whether non-users potentially overestimate the quality of their data or if there was no notable improvement of the data quality among local authorities using software based on a collaborative approach.

\subsection{External Environment}

Concerning the external environment, the data collected in the survey indicated an influence of external pressure due to the existing collaboration in other local authorities on the decision for adoption. In the context of municipal administration, there is no competition in the classical business sense so that the result is due to pressure only trough other local authorities, which in regard to collaboration are seen as partners. The knowledge of other local authorities maintaining and enhancing the quality of their data in collaboration with each other can have a supportive impact on the decision for the adoption of such a software solution.

Furthermore, the finding that other local authorities produce better performance with higher quality due to higher data quality can have positive effects on the adoption decision as well. The influence of guidelines of legal data protection requirements as well as internal compliance rules could not be confirmed. Against the background of the strict regulation of municipal administration and strict rated data protection requirements, this result is surprising. The highly perceived restrictions by legal as well as internal regulations do not seem to have such an impact on adoption decisions as expected so that an exogenous restriction for the establishment of CDMS can possibly be excluded. 


\section{Conclusion and Further Research}

The present paper aims to provide a first explanatory approach towards the influencing factors that play a role for the decision on the adoption of software for the collaborative maintenance and improvement of data quality. The results show that 5 of the 8 previously formulated hypotheses regarding the possible influencing factors could be confirmed based on the collected data. Accordingly, the perceived obstacles for the implementation of a software solution for collaborative maintenance and improvement of data quality have a negative influence on the decision for adoption, and so does a high complexity of the IT infrastructure of the organization. However, the decision is positively influenced by the existence of standards, e.g. XÖV and the recognized importance of these standards as well as the external pressure that other public administrations improve their data quality through collaboration.

Contrary, the participating public administrations indicated that strict data protection requirements provided by law as well as internal compliance rules have negatively influenced the decision to adopt. This can be evaluated in two different ways. First, legal obligations can negatively impact the citizens through a decreased quality of master data and hence more errors in the public service processes. At the same time, such barriers highlight the importance of data privacy, which are very important to citizens, especially in countries such as Germany.

IS managers might learn that data quality can be improved following a collaborative approach. In order to support CDMS standards, a positive information sharing culture and a complex IT infrastructure might help managers to be successful improving master data quality. At the same time, the exchange of master data can lead to data privacy issues, why it is important to apply data protection measures.

The presented findings come with some limitations. The study is limited to Germany, as only German public administrations were chosen using convenience sampling within the groups with less than 100.000 inhabitants. In Addtion, with respect to the sample consisting of IT and organizational staff, the results linked to data quality should be interpreted with caution. Thus, the authors suggest a common method bias, in the way that the IT staff evalute the quality of the data for which they are responsible as higher than it really is.

As a next step, we aim to deepen our understanding of influencing factors in this context by conducting several semi-structured interviews as well as document analysis. Future research in this field may build on this foundation and expand the model with additional technological, organizational, or environmental factors.

\section{References}

[1] NRW Federal State Government, "E-Government Studie NRW," 2003. [Online]. Available: http://www.mik.nrw.de/fileadmin/user_upload/editors/import /inn/doks/egov/egovstudie2003.pdf .

[2] BITKOM, "Öffentliche Hand gibt über 20 Milliarden Euro für ITK aus," 2014. [Online]. Available: http://www.bitkom.org/de/themen/37244_78084.aspx

[Accessed: 03-May-2015].

[3] M. Miller, "E-Government und Verwaltungsmodernisierung - Potenziale und Probleme," in Verwaltungswissenschaften - Aktuelle Schwerpunkte und Herausforderungen, J. Stember and W. Beck, Ed. Lit Verlag, 2008 .

[4] B. Otto, A. Weisbecker, and D. Gizanis, "Stammdatenmanagement : Datenqualität für Geschäftsprozesse," HMD Prax. der Wirtschaftsinformatik, vol. 48, pp. 5-16, 2011.

[5] C. Jochheim-Wirtz and M. Schürmann, "E-Government in Südwestfalen: Die geokodierte interkommunale Adressdatenbank," Eild. - Monatszeitschrift des Landkreistages Nord., pp. 70-72, 2012.

[6] L. Tornatzky and M. Fleischer, The processes of technological innovation. Lexington, USA: Lexington Books, 1990.

[7] P. Y. K. Chau and K. Y. Tam, "Factors Affecting the Adoption of Open Systems: An Exploratory Study," MIS Q., vol. 21, pp. 1-24, 1997.

[8] C. L. Iacovou, I. Benbasat, and A. S. Dexter, "Electronic Data Interchange and Small Organizations: Adoption and Impact of Technology," MIS Q., vol. 19, pp. 465-485, 1995.

[9] P. Ifinedo, "Internet / E-Business Technologies Acceptance in Canada's SMEs: Focus on Organizational and Environmental Factors," in E-Business - Applications and Global Acceptance, P. Ifinedo, Ed. Rijeka, Croatia: InTech, 2012.

[10] R. Linden, "Learning to Manage Horizontally: The Promise and Challenge of Collaboration," Public Manag., vol. 85 , pp. 8-11, 2003.

[11] D. Stoller-Schai, "E-Collaboration: Die Gestaltung internetgestützter kollaborativer Handlungsfelder," Universität St. Gallen, 2003.

[12] K. Riemer, S. Stieglitz, and C. Meske, "From Top to Bottom: Investigating the Changing Role of Hierarchy in 
Enterprise Social Networks,” Bus. Inf. Syst. Eng., vol. 57, pp. 197-212, 2015.

[13] S. Stieglitz, K. Riemer, and C. Meske, "Hierarchy or Activity? The Role of Formal and Informal Influence in Eliciting Responses From Enterprise Social Networks," in European Conference on Information Systems, 2014.

[14] S. Stieglitz, S. Schallenmüller, and C. Meske, "Adoption of Social Media for Internal Usage in a Global Enterprise," in AINA, 2013.

[15] N. Kock, R. Davison, R. Wazlawick, and R. Ocker, "Ecollaboration: A look at past research and future challenges," J. Syst. Inf. Technol., vol. 5, pp. 1-8, 2001.

[16] K. Nakatani, T.-T. Chuang, and D. Zhou, "Data Synchronization Technology: Standards, Business Values and Implications," Commun. Assoc. Inf. Syst., vol. 17, 2006.

[17] A. Meier, eDemocracy \& eGovernment. Berlin/Heidelberg, Germany: Springer, 2009.

[18] S. Trang, S. Zander, and L. M. Kolbe, "Dimensions of Trust in the Acceptance of Inter-organizational Information Systems in Networks: Towards a Socio-technical Perspective," in PACIS, 2014.

[19] J. M. Pawlowski, M. Bick, M. Martensen, R. Peinl, S. Thalmann, R. Maier, and et al., "Social knowledge environments,” Bus. Inf. Syst. Eng., vol. 6, pp. 81-88, 2014.

[20] C. Wang, M. Zuo, and X. Quan, "Knowledge Sharing of Senior Employees in the Context of Task-based Cooperation: A Game Theoretic Analysis," in PACIS, 2014.

[21] M. Mohammadjafari, "E-Collaboration in PreProduction Process in Manufacturing Industries for Enhancing the Key Performance," J. Eng. Econ. Dev., vol. 2, pp. 12-22, 2015 .

[22] J. Von Lucke and H. Reinermann, "Speyerer Definition von Electronic Government," 2001. [Online]. Available: http://foev.dhv-speyer.de/ruvii/ . [Accessed: 04-Apr-2015].

[23] P. Karger, O. Rüß, and N. vom Scheidt, E-Government. Handbuch zur Verwaltungsreform. Wiesbaden, Germany: VS Verlag für Sozialwissenschaften, 2011.

[24] J. Rose, J. Persson, L. Heeager, and Z. Irani, "Managing e-Government: Value positions and relationships," Inf. Syst. $J$., vol. 25, pp. 531-571, 2015.

[25] D. Zheng, J. Chen, L. Huang, and C. Zhang, "EGovernment adoption in public administration organizations: Integrating institutional theory perspective and resource based view," Eur. J. Inf. Syst., vol. 22, pp. 221-234, 2013.

[26] J. Becker, B. Niehaves, and K. Ortbach, "Does the answer lie in collaboration? - A case study on e-government and societal aging," in ECIS, 2009.

[27] A. Schellong and D. Mans, "Citizens preferences towards one-stop government," in Annual National Conference on Digital Government Research, 2004.
[28] O. Reinhold and R. Alt, "Usability of CRM Systems as Collaboration Infrastructures in Business Networks," in Bled eConference, 2008.

[29] C. Loser, C. Legner, and D. Gizanis, "Master data management for collaborative service processes," in International Conference on Service Systems and Service Management, 2004.

[30] J. Kokemüller, "Stammdatenmanagement - Strategie für Zukunft, Lösungen von Heute," in 5. Stuttgarter Softwaretechnik Forum Stammdatenmanagement, Stuttgart, Germany, 2009.

[31] B. Otto and K. Weber, "Data Governance," in Daten und Informationsqualität - Auf dem Weg zur Information Excellence, K. Hildebrand, M. Gebauer, H. Hinrichs, and M. Mielke, Eds. Wiesbaden, Germany: Vieweg+Teubner Verlag, 2011.

[32] N. Bhansali, "The Role of Data Governance in an Organization," Data Gov. Creat. Value from Inf. Assets, pp. 1-19, 2014.

[33] P. Simon and D. Cervo, "Master Data Management," Multi-domain Master Data Manag. Adv. MDM Data Gov. Pract., pp. 3-10, 2015.

[34] L. K. Cheong and V. Chang, "The Need for Data Governance: A Case Study," in ACIS, 2007.

[35] E. M. Rogers, Diffusion of Innovations. New York, USA: Free Press, 1983

[36] W. H. Starbuck, Organizations and their environments. Chicago, USA: Rand McNally, 1976.

[37] J. Hage, Theories of organizations: Forms, process and transformation. New York, USA: John Wiley \& Sons, 1980.

[38] J. D. Thompson, Organizations in action. New York, USA: McGraw-Hill, 1967.

[39] E. B. Swanson, "Information Systems Management among Organizations," Manage. Sci., vol. 40, pp. 1069 1092, 1995.

[40] T. Teo and Y. Pian, "A Contingency Perspective on Internet Adoption and Competitive Advantage," Eur. J. Inf. Syst., vol. 12, pp. 78-92, 2003.

[41] J. L. Gibbs and K. L. Kraemer, "A Cross-Country Investigation of the Determinants of Scope of E-Commerce Use: An Institutional Approach," Electron. Mark., vol. 14, pp. 124-137, 2004.

[42] K. Zhu, K. L. Kraemer, and S. Xu, "Electronic business adoption by European firms: A cross-country assessment of the facilitators and inhibitors," Eur. J. Inf. Syst., vol. 12, pp. 251-268, 2003.

[43] A. Soares-Aguiar and A. Palma-dos-Reis, "Why Do Firms Adopt E-Procurement Systems? Using Logistic Regression to Empirically Test a Conceptual Model," IEEE Trans. Eng. Manag., vol. 55, pp. 120-133, 2008. 
[44] I. Brown and J. Russell, "Radio frequency identification technology: An exploratory study on adoption in the South African retail sector," Int. J. Inf. Manage., vol. 27, pp. 250 265, 2007.

[45] Q. Cao, J. Baker, J. Wetherbe, and V. Gu, "Organizational Adoption of Innovation: Identifying Factors that Influence RFID Adoption in the Healthcare Industry," in ECIS, 2012.

[46] G. Larosiliere, C. Meske, and L. Carter, "Determinants of Social Network Adoption: A Country-Level Analysis," in HICSS, 2015, pp. 3424-3433.

[47] I. Troshani, C. Jerram, and M. Gerrard, "Exploring the organizational adoption of Human Resources Information Systems (HRIS) in the Australian public sector," in ACIS, 2010.

[48] A. Bhattacherjee and S. C. Park, "Why end-users move to the cloud: a migration-theoretic analysis," Eur. J. Inf. Syst., vol. 23, pp. 357-372, 2014.

[49] V. Venkatesh, M. Morris, G. Davis, and F. Davis, "User Acceptance of Information Technology: Toward a Unified View," MIS Q., vol. 27, pp. 425-478, 2003.

[50] R. Y. Wang and D. M. Strong, "Beyond Accuracy: What Data Quality Means to Data Consumers," J. Manag. Inf. Syst., vol. 12, pp. 5-33, 1996.

[51] K. Ortbach, T. Brockmann, and S. Stieglitz, "Drivers for the Adoption of Mobile Device Management Organizations," in ECIS, 2014.

[52] KGSt, "KGSt | Mitgliedschaft," 2015. [Online]. Available: http://www.kgst.de/mitgliedschaft .

[53] K. K. Wong, "Handling small survey sample size and skewed dataset with partial least square path modelling," Vue Mag. Mark. Res. Intell. Assoc., pp. 20-23, 2010.

[54] J. F. Hair, C. M. Ringle, and M. Sarstedt, "PLS-SEM: Indeed a Silver Bullet," J. Mark. Theory Pract., vol. 19, pp. 139-152, 2011.

[55] D. Gefen and D. W. Straub, "A practical guide to factorial validity using PLS-Graph: tutorial and annotated example," Commun. AIS, vol. 16, pp. 91-109, 2005.

[56] W. W. Chin, "The Partial Least Square Approach to Structural Equation Modeling," in Modern Methods for Business Research, 1998, pp. 295-336.

[57] A. Cacaci, "Change Management - Widerstände gegen Wandel: Plädoyer für ein System der Prävention," DUV J., 2006.

\section{Appendix A}

\section{Constructs and Items}

Perceived Benefits (Likert 1-7, strongly disagree to strongly agree) (Source: $[49]$ )

The CDMS improves the productivity of employees. The CDMS improves the service for customers (citizens).

Perceived Barriers (Likert 1-7, strongly disagree to strongly agree, reverse coded) (Source: [48])

The implementation efforts are high.

The willingness of the employees to share data with other municipal institutions is low.

Current Master Data Quality (Likert 1-7, strongly disagree to strongly agree) (Source: [50])

The current quality of master data in our organisation is high regarding the completeness.

The current quality of master data in our organisation is high regarding the accuracy.

Complexity (Source: [7])

Please estimate the approximate number of different systems ("Fachverfahren"). (<5, 5-9, 10-14, 15-29, 30-49, 50-100, >100)

Please estimate the approximate number of different data formats of master data in your organisation. $(<3,3-4,5-9$, $10-14,15-19,20-25,>25)$

Existence of Standards (Likert 1-7, strongly disagree to strongly agree) (Source: developed)

There exist standards for the collection of data (methods and processes).

There exist standards for filing data (formats and structures).

There exist standards for the exchange of data with other municipal institutions.

Importance of Standards (Likert 1-7, strongly

disagree to strongly agree) (Source: developed)

To improve the master data quality, it is important to have standards for the collection of data

To improve the master data quality, it is important to have standards for filing data.

To improve the master data quality, it is important to have standards for the exchange of data with other municipal institutions.

CDMS-Usage in Other Public Administrations (Likert 1-7, strongly disagree to strongly agree) (Source: developed)

Other municipal administrations internally use software to improve master data quality (intra-institutional). Other municipal administrations use software to collaboratively improve master data quality together with other institutions (inter-instutitional).

Strict Date Protection Directives (Likert 1-7, strongly disagree to strongly agree) (Source: developed)

There exist strict legal data protection directives.

There exist strict internal compliance requirements regarding data protection.

Adoption of CDMS (Yes/No) (Source: [7], [50])

My institution currently uses a CDMS. 